\title{
„Push and Pull“-Technik für Platten mit Schlauch
}

Dankward Höntzsch

Um beim minimalinvasiven Einschieben den einmal präparierten Weg für Platten zu halten, hat sich bewährt, dass das Ende mit einem Faden armiert und dieser nachgezogen wird.

In empfindlichen Regionen wie z. B. der Beckenregion, ob nun über einen ilioinguinalen Zugang oder gemischten Zugang Stoppa/pararectum-Zugang kombiniert mit dem Fenster über der Symphyse, werden Platten eingeschoben und müssen manchmal von der Biegung her korrigiert oder gegen eine längere oder kürzere ersetzt werden.

Um den einmal präparierten Kanal ohne Schaden wieder zu benutzen, hat es sich bewährt, die Platte mit einem geeigneten Schlauch (nicht zu groß/nicht zu klein) zu armieren und dann die Platte mit dem anhängenden Schlauch zurückziehen. Die dann korrigierte oder neu gewählte Platte kann dann wieder in den Schlauch eingeschoben werden und die Platte wird ohne „Widerhaken“ und ohne Gefahr für die unterminierten Gewebeanteile in den bereits vorgegebenen Weg eingezogen ( $\triangleright$ Abb. 1 und 2).

Korrespondenzadresse

Prof. Dr. Dankward Höntzsch

Tübingen

Hoentzsch@t-online.de

Bibliografie

DOI https://doi.org/10.1055/a-0647-1545

OP-JOURNAL 2018; 34: 177 @ Georg Thieme Verlag KG Stuttgart · New York ISSN 0178-1715

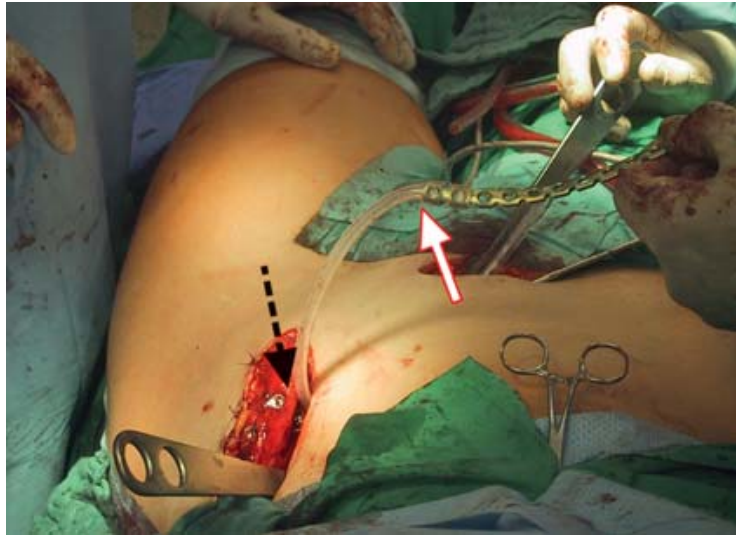

- Abb. 1 Die angeformte Platte wird an einen vorher sicher und sanft (z. B. mit einer Kornzange) eingezogenen Drainageschlauch angeknotet.

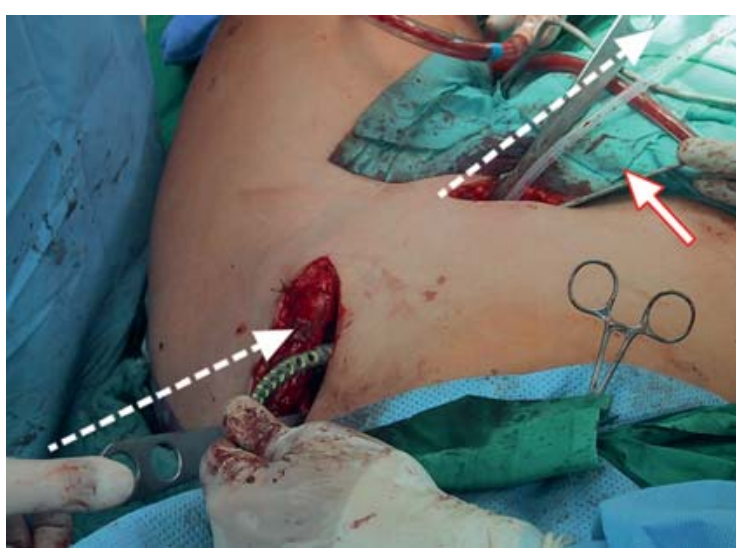

- Abb. 2 So kann die Platte schonend und immer im gleichen Kanal eigezogen werden. Zudem ist das eckige Ende geschützt und die Platte schlupft ohne Gefahr etwas aufzuladen hinein und heraus. 